\title{
A Comparison of Flavorless Electronic Cigarette-Generated Aerosol and Conventional Cigarette Smoke on the Survival and Growth of Common Oral Commensal Streptococci
}

\author{
Giancarlo A. Cuadra ${ }^{1}$, Maxwell T. Smith ${ }^{2}$, John M. Nelson ${ }^{3}$, Emma K. Loh $^{1}$ and \\ Dominic L. Palazzolo ${ }^{4, *}$ \\ 1 Department of Biology, Muhlenberg College, Allentown, PA 18104, USA; \\ giancarlocuadra@muhlenberg.edu (G.A.C.); el251159@muhlenberg.edu (E.K.L.) \\ 2 Department of Medical Laboratory Science, School of Allied Health Sciences, Lincoln Memorial University, \\ Harrogate, TN 37752, USA; maxwellsmith1572@gmail.com \\ 3 Department of Biology, School of Mathematics and Sciences, Lincoln Memorial University, Harrogate, \\ TN 37752, USA; john.nelson@LMUnet.edu \\ 4 Department of Physiology, DeBusk College of Osteopathic Medicine, Lincoln Memorial University, \\ Harrogate, TN 37752, USA \\ * Correspondence: domenico.palazzolo@LMUnet.edu
}

Received: 21 March 2019; Accepted: 8 May 2019; Published: 14 May 2019

\begin{abstract}
Background: The use of electronic cigarettes (ECIG) has become very common. Consequently, critical analysis of the biological effects of ECIG aerosol deserves attention. Flavorless ECIG aerosol is known to comprise fewer harmful constituents than cigarette smoke. Therefore, we hypothesize that aerosol has less immediate effect on the viability of oral commensal streptococci than smoke. Methods: Survival and growth of four strains of commensal streptococci were measured after exposure to flavorless ECIG aerosol \pm nicotine and smoke. Peristaltic pumps were used to transport aerosol or smoke into chambers containing recently seeded colony-forming units (CFUs) of the oral commensal streptococci on agar plates. Bacterial survival and growth, based on colony counts and sizes, were determined $24 \mathrm{~h}$ post-exposure. Additionally, aerosol or smoke were delivered into chambers containing pre-adhered streptococci to plastic coverslips and biofilm formation was determined $24 \mathrm{~h}$ post-exposure via scanning electron microscopy. Results: The results suggest that flavorless aerosol \pm nicotine has a modest effect on bacterial growth both as colonies on agar and as biofilms. In contrast, smoke dramatically decreased bacterial survival and growth in all parameters measured. Conclusion: Unlike cigarette smoke, flavorless ECIG aerosol has only a small effect on the survival and growth of oral commensal streptococci.
\end{abstract}

Keywords: ECIG; E-liquid; vaping; smoking; aerosol; streptococci; oral commensal bacteria

\section{Introduction}

The use of electronic cigarettes (ECIG), referred to as vaping, has gained immense popularity in recent times [1]. Cigarette smoke is known to contain thousands of detrimental compounds, but the constituents of flavorless ECIG aerosol are few. In general, ECIG-liquid (E-liquid) consists of propylene glycol and/or vegetable glycerin, nicotine ranging from 0 to $>24 \mathrm{mg} / \mathrm{mL}$ and a variety of flavors [2]. While vaping on ECIG devices is commonplace, as of yet there is no clear evidence of the potential issues its usage could cause. For this reason, the physiological effects of ECIG aerosol should be seriously investigated. 
Currently, there are few studies regarding effects of ECIG-generated aerosol on physiological systems as compared to cigarette smoke. A few reports claim that ECIG use is as dangerous (or more dangerous) than traditional smoking [3-5]. E-liquid flavorings have also recently been reported to induce inflammatory and oxidative responses in human monocytic cell lines [6]. Similarly, various flavored E-liquids have a toxic effect on stem cells and terminally differentiated cell lines [7]. Moreover, human bronchial epithelial as well as oral epithelial cell lines exposed to ECIG-generated aerosol with flavorings increased pro-inflammatory cytokine production and caused other adverse effects on the biology of these cell models [8-10]. All these studies indicate that it is the flavorings, and not the base humectants (i.e., propylene glycol and/or vegetable glycerin) that is detrimental to exposed tissues and consequently deserves more attention to better inform the public, especially since many young adults are enticed by the myriad of flavors. On the other hand, the purpose of this study is to investigate the effects of a flavorless ECIG-generated aerosol on the survival and growth of several strains of oral commensal streptococci, important bacteria needed for the formation of biofilms. To our knowledge, there are no studies that have addressed the effects of flavorless ECIG aerosol on any oral bacteria. Analysis of the effects of a flavorless aerosol on the oral microbiome is important because it will allow for baseline quantification of streptococcal survival and growth. This information will eventually be useful in teasing out the absolute effect of individual flavors from the effects of the base humectants. For example, is the effect of the aerosol due to the vaporized flavors, the vaporized humectants or both? Thus, the results of this investigation will ultimately serve as a preamble for future studies related to the effects of flavored ECIG aerosol on the oral microbiome.

The oral cavity contains a vast diversity of commensal, opportunistic and sometimes pathogenic bacteria. The most common types of commensal bacteria are streptococci [11,12], which are found in individuals at any level of oral health and disease [13,14]. Among these bacteria, some of the most common species are Streptococcus gordonii, Streptococcus intermedius, Streptococcus mitis and Streptococcus oralis [15-17]. All four of these species are crucial in the development of oral biofilms on both soft and hard surfaces within the mouth $[13,18,19]$. These species are considered commensal early colonizers [20-22]. All four species are beneficial to the host oral cavity in the context of their interactions with pathogenic species related both to caries and periodontal disease [23-28]. By extension, since oral health and overall general health are directly correlated, any disruption to the bacterial flora within the oral cavity could lead to systemic diseases, especially certain types of cardiovascular disease [29]. For this reason, it is important to examine how vaping affects the oral commensal microbiota.

Smoking has been reported to be a leading risk factor for caries and periodontal disease [30-33] and is known to affect the subgingival oral microbiome in situ considerably [34]. No studies (to our knowledge) are available to show how ECIG aerosol specifically affects oral commensal streptococci known to provide a protective barrier against external insults. Since S. gordonii, S. intermedius, S. mitis and $S$. oralis are crucial in the development of oral biofilms on both soft and hard surfaces within the mouth, the specific aim of this work is to test the impact of flavorless ECIG aerosol and compare it to conventional cigarette smoke on the survival and growth of oral commensal streptococci.

\section{Materials and Methods}

\subsection{Reagents and Supplies}

All reagents and supplies for conducting these investigations were purchased from Thermo Fisher Scientific (Waltham, MA, USA) unless otherwise noted.

\subsection{Bacterial Strains}

S. gordonii DL1, S. intermedius 0809 , S. mitis UF2 and S. oralis SK139 were kindly provided by Dr. Robert Burne from the University of Florida. All strains were grown in brain heart infusion (BHI) broth with $5 \mu \mathrm{g} / \mathrm{mL}$ hemin or $\mathrm{BHI}$ agar at $37^{\circ} \mathrm{C}$ and $5 \% \mathrm{CO}_{2}$. Bacterial stocks were stored at $-80{ }^{\circ} \mathrm{C}$. 


\subsection{E-Liquid}

E-liquid was composed of 50\% propylene glycol and 50\% vegetable glycerin (i.e., glycerol) with or without $( \pm) 20 \mathrm{mg} / \mathrm{mL}$ of (S)-(-)-nicotine (Alpha Aesar, Tewksbury, MA, USA). No flavors were added. This nicotine concentration on a per cigarette equivalent is higher than the typical concentration of nicotine in a tobacco cigarette [35], but is comparable to the high end nicotine concentration found in a number of commercially available E-liquids.

\subsection{Exposure Apparatus}

Bacterial samples were exposed to either air, flavorless ECIG aerosol $\pm 20 \mathrm{mg} / \mathrm{mL}$ nicotine or cigarette smoke following already established protocols [36,37]. Briefly, Cole-Palmer Master Flex L/S peristaltic pumps (Vernon Hills, IL) and tubing were used to simulate puffing and transport air, smoke or aerosol into an acrylic chamber, as shown in Figure 1. Peristalsis and flow rates were adjusted to $400 \mathrm{~mL} / \mathrm{min}$ or $33.3 \mathrm{~mL}$ in five seconds as indicated in Table 1. Puffing was conducted at $5 \mathrm{~s}$ (pumps active) followed by a 10-second rest period (pumps inactive). The puffing protocol consisted of 0,10 , 25, 50 and 75 puffs. Values of total nicotine exposure in the acrylic chamber are shown in Table 1. All pump-puffing experiments were conducted within a P20 Purair ductless fume hood (Airscience, Fort Myers, FL, USA) with a high efficiency particulate air (HEPA) filter.

\subsection{Distribution of Aerosol and Smoke in the Exposure Chamber}

Three $100 \mathrm{~mm}$ plates containing $10 \mathrm{~mL}$ of $\mathrm{BHI}$ broth were placed in the exposure chamber. According to Figure 1, the plate in position 1 is the closest to the source of aerosol or smoke and the plate in position 3 is the farthest away. The rubber cap closest to position 3 in the chamber was perforated so as to not completely cut off ventilation, and thus limiting the buildup of excess aerosol or smoke. BHI broth in three plates was exposed to flavorless ECIG aerosol with $20 \mathrm{mg} / \mathrm{mL}$ nicotine and cigarette smoke for a total of 10, 25, 50 and 75 puffs following above protocols. Concentrations of nicotine in the BHI broth of plate 1, plate 2 and plate 3 (Figure 1) were evaluated by high-performance liquid chromatography (HPLC).

\subsection{High-Performance Liquid Chromatography (HPLC) Determination of Nicotine}

Standard solutions of 99\% (S)-(-)-nicotine, were prepared in BHI broth at concentrations of 0.4 , 0.2 and $0.1 \mathrm{mg} / \mathrm{mL}$. Standards and samples of BHI exposed to 10, 25, 50 or 75 puffs of flavorless ECIG aerosol with nicotine or conventional cigarette smoke were analyzed by HPLC coupled with photodiode array detection as previously described [38,39]. A Shimadzu HPLC system (Columbia, MD) was used to quantitate nicotine and included the following: a photodiode array detector (SPD-M20A), dual pumps (LC-20AT), a column oven (CTO-20A), an in-line membrane degasser (DGU-20A3R) and a Rheodyne 7725I manual injector with $20 \mu \mathrm{L}$ loop ( $40 \mu \mathrm{L}$ injection volume). Nicotine was separated on a Phenomenex (Torrance, CA, USA) 15-cm, Kinetex ${ }^{\circledR} 5 \mu \mathrm{m}$ reversed phase C-18 column preceded by a Phenomenex Security Guard. Column temperature was maintained at $35^{\circ} \mathrm{C}$. Nicotine was detected at ultraviolet (UV) wavelengths between 230 and $300 \mathrm{~nm}$ and quantifications were carried out at $260 \mathrm{~nm}$. The mobile phase was delivered at a rate of $1 \mathrm{~mL} /$ minute in gradient fashion where mobile phase $\mathrm{A}$ consisted of $10 \%$ acetonitrile in $20 \mathrm{mM}$ ammonium formate adjusted to $\mathrm{pH} 8.5$ with $50 \%$ ammonium hydroxide and mobile phase B consisted of 100\% acetonitrile. Mobile phase A decreased from $100 \%$ to $80 \%$ from 0 to $10 \mathrm{~min}$, decreased from $80 \%$ to $20 \%$ from 10 to $20 \mathrm{~min}$, increased from $20 \%$ to $100 \%$ from 20 to $21 \mathrm{~min}$ and remained at 100\% till the end of the run time at $30 \mathrm{~min}$. Mobile phase B increased from $0 \%$ to $20 \%$ from 0 to $10 \mathrm{~min}$, increased from $20 \%$ to $80 \%$ from 10 to $20 \mathrm{~min}$, decreased from $80 \%$ to $0 \%$ from 20 to $21 \mathrm{~min}$ and remained at $0 \%$ till the end of the run time at $30 \mathrm{~min}$. The nicotine standard curve was linear $\left(R^{2}=0.9998\right)$ and nicotine eluted at a retention time of $10.5 \mathrm{~min}$. Chromatographic parameters were PC-controlled using a Shimadzu Lab Solutions work station (Columbia MD). 


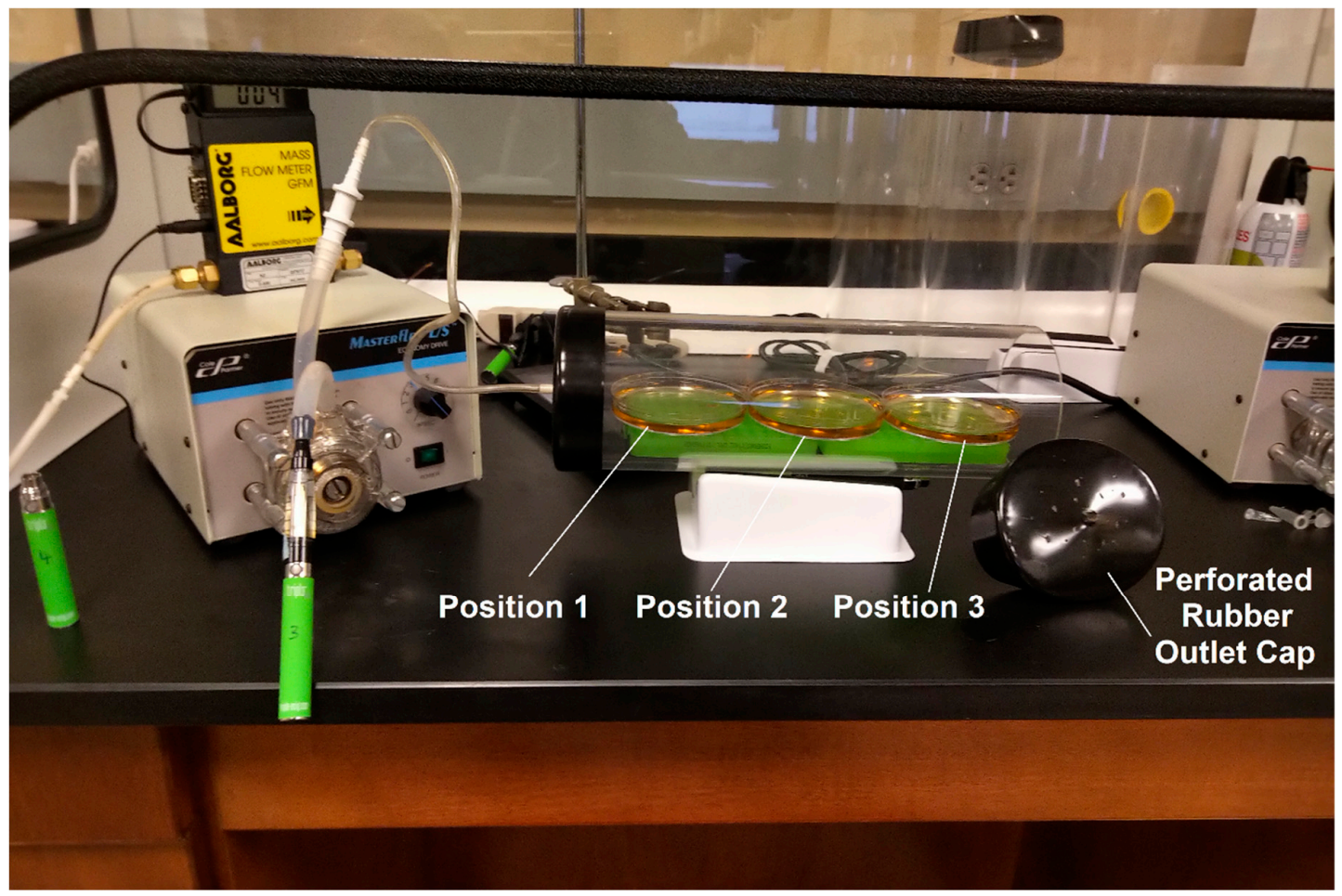

Figure 1. Exposure apparatus for flavorless electronic cigarettes (ECIG) aerosol and cigarette smoke. Peristaltic pumps, tubing and acrylic chamber containing three plates numbered 1, 2 and 3 according to their relative position with respect to the aerosol or smoke source (tubing connection to chamber). Mass flow meter (small yellow and black machine) was used to calibrate the flow of materials at 400 $\mathrm{mL} / \mathrm{min}$. The rubber outlet cap is removed to show perforations. All materials are shown inside a Purair ductless fume hood.

Table 1. Pump/chamber parameters and nicotine concentrations within the exposure chambers.

\begin{tabular}{|c|c|c|}
\hline & Smoke Pump/Chamber & Aerosol Pump/Chamber \\
\hline Pump Flow Rate (mL/min) & 400 & 400 \\
\hline Puff Duration (s) & 5 & 5 \\
\hline Puff Volume (mL) & 33.3 & 33.3 \\
\hline Nicotine (mg/cigarette) ${ }^{a}$ & 0.92 & 2.80 \\
\hline Nicotine (mg/puff) ${ }^{b}$ & 0.06 & 0.19 \\
\hline Nicotine Flow ( $\mu \mathrm{g} / \mathrm{puff} / \mathrm{mL})$ into Chamber & 1.8 & 5.7 \\
\hline Exposure Chamber Volume $\left(\mathrm{cm}^{3}\right)$ & 2126 & 2126 \\
\hline $\begin{array}{c}\text { Nicotine Delivered to Chamber }(\mathbf{m g}) \\
0 \text { puffs }(0.0 \text { cigarettes }) \\
25 \text { puffs }(1.7 \text { cigarettes }) \\
50 \text { puffs }(3.3 \text { cigarettes }) \\
75 \text { puffs }(5.0 \text { cigarettes })\end{array}$ & $\begin{array}{l}0.0 \\
1.5 \\
3.0 \\
4.5\end{array}$ & $\begin{array}{c}0.0 \\
4.8 \\
9.5 \\
14.3\end{array}$ \\
\hline $\begin{array}{c}\text { Nicotine Concentration in Chamber }\left(\mu \mathrm{g} / \mathrm{cm}^{3}\right)^{\mathrm{c}} \\
0 \text { puffs }(0.0 \text { cigarettes }) \\
25 \text { puffs }(1.7 \text { cigarettes }) \\
50 \text { puffs ( } 3.3 \text { cigarettes }) \\
75 \text { puffs (5.0 cigarettes) }\end{array}$ & $\begin{array}{l}0.0 \\
0.7 \\
1.4 \\
2.1\end{array}$ & $\begin{array}{l}0.0 \\
2.2 \\
4.5 \\
6.7\end{array}$ \\
\hline
\end{tabular}

${ }^{a}$ For smoke, the value of mg nicotine per Marlboro ${ }^{\circledR}$ Red cigarette [35]. For aerosol, the value $2.8 \mathrm{mg} /$ cigarette is based on $9.3 \mu \mathrm{L}$ of E-liquid ( $20 \mathrm{mg} / \mathrm{mL}$ nicotine) aerosolized per puff and that 15 puffs is equivalent to one cigarette [40]. ${ }^{\mathrm{b}}$ One cigarette is equivalent to 15 puffs. ${ }^{\mathrm{c}}$ These values assume that all nicotine remains within the chamber, which is not the case since the exposure chambers are fitted with rubber end caps perforated with small holes to allow venting of the exposure chambers [36,37]. 


\subsection{Colony-Forming Units (CFUs)}

Starter overnight cultures of all four strains of bacteria were adjusted to optical density (OD) of 1 at $595 \mathrm{~nm}$. For all species tested, an OD of 1.0 yields a range of 2 to $4 \times 10^{9} \mathrm{CFU} / \mathrm{mL}$. Then, bacteria were serially diluted (1:10) to numbers permissible for CFU counting and $20 \mu \mathrm{L}$ of each species were plated in triplicate on BHI agar plates. As soon as the $20 \mu \mathrm{L}$ volume dried into the agar, bacteria were exposed uncovered to air, flavorless ECIG aerosol ( $\pm 20 \mathrm{mg} / \mathrm{mL}$ nicotine) or cigarette smoke for up to 75 puffs. Following exposures, plates were incubated at $37^{\circ} \mathrm{C}$ and $5 \% \mathrm{CO}_{2}$ for $24 \mathrm{~h}$. The next day, colonies were digitally photographed using a Moticam 1080 HDMI and USB camera (Motic ${ }^{\circledR}$, Richmond, British Columbia, Canada) attached to a Fisher brand stereomicroscope and counted. Average colony sizes (as indexed by the area of individual colonies) were determined using the Moticam supplied on-board camera software $\left(\right.$ Motic $^{\circledR}$, Richmond, BC, Canada).

\subsection{Biofilm Biomass}

Starter overnight cultures of bacteria were adjusted to OD $595 \mathrm{~nm}$ of 1.00. After adjustment, $100 \mu \mathrm{L}$ of each culture was seeded separately on sterile and untreated plastic coverslips $(13 \mathrm{~mm}$ diameter) 12-well plates. Bacteria were allowed to adhere to the surface of the coverslips without agitation for $1 \mathrm{~h}$ at $37{ }^{\circ} \mathrm{C}, 5 \% \mathrm{CO}_{2}$ and the excess unbound bacteria were washed 3 times with $0.5 \mathrm{~mL}$ phosphate-buffered saline (PBS). Excess liquid on the coverslips was removed and the 12-well plates containing the coverslips were exposed uncovered to 75 puffs air, flavorless ECIG-generated $( \pm 20 \mathrm{mg} / \mathrm{mL}$ nicotine) or cigarette smoke. Following exposure, $1 \mathrm{~mL}$ of $50 \%$ BHI broth (v/v in sterile water) was added to each well of the 12-well plate ensuring that exposed coverslips were completely submerged. Exposed bacteria were subsequently incubated without agitation and without media exchange for $24 \mathrm{~h}$ at $37^{\circ} \mathrm{C}, 5 \% \mathrm{CO}_{2}$ to allow for biofilm growth on the coverslips. At the end of the 24- $\mathrm{h}$ incubation period, BHI broth was removed from the wells and the coverslips were washed 3 times with $1 \mathrm{~mL}$ PBS to remove excess unbound bacteria. Biofilms were fixed with $1 \mathrm{~mL}$ of $4 \%$ formaldehyde for at least $30 \mathrm{~min}$. Coverslips were then processed for scanning electron microscope (SEM) imaging (described below).

\subsection{Biofilm Processing for Scanning Electron Microscope (SEM) Imaging}

The $4 \%$ formaldehyde was removed from each well and each coverslip was rinsed two times with $1 \mathrm{~mL}$ of deionized water. The biofilms on the coverslips were then dehydrated using an increasing alcohol gradient (i.e., $30 \mathrm{~min}$ in each of 50, 70, 90 and 100\% ethanol) followed by chemical drying with $98 \%$ hexamethyldisilizane for $30 \mathrm{~min}$. The coverslips with attached biofilms were then removed from the 12-well plates and air dried for 5 to $10 \mathrm{~min}$ before mounting on to $13 \mathrm{~mm}$ aluminum pin-type stubs (Structure Probe, Inc. (SPI), West Chester, PA, USA). Conductive, $12 \mathrm{~mm}$ diameter, double-sided carbon-impregnated adhesive disks (SPI) were used to adhere the coverslips to the stubs and 1 to $2 \mathrm{~h}$ was allowed for complete adherence. In the mounting process, extreme care was used to ensure the side of the coverslip with the bacterial biofilm was facing up and not disrupted. The mounted bacterial biofilms were then sputter coated using a Hummer IV-A sputtering system (Anatech Ltd., Alexandria, VA, USA) and plated with $300 \AA ̊$ of 1:1 gold:palladium. SEM images of biofilms grown on coverslips were taken with a TOPCON ABT-60 microscope at an acceleration voltage of $15 \mathrm{kV}$ and a magnification of $450 \times$.

\subsection{Statistical Analysis}

Mean and standard error of the mean (SE) were calculated for nicotine in BHI broth. One-way analysis of variance (ANOVA) followed by Newman-Keuls multiple comparison test analysis was used to determine differences in nicotine concentrations between plate positions 1, 2 and 3 after 10, 25, 50 and 75 puffs of flavorless ECIG aerosol with $20 \mathrm{mg} / \mathrm{mL}$ nicotine or conventional cigarette smoke. CFUs were visually counted and the average of three largest colonies in each quadrant of an agar 
plate were used to determine mean colony size for all bacteria at every exposure. Mean and standard error (SE) were calculated for CFU counts and colony size. Statistical variance between groups was determined using two-way ANOVA, followed by Bonferroni post hoc analysis. Differences were considered statistically significant when $p<0.01$.

\section{Results}

\subsection{Distribution of Aerosol and Smoke in the Exposure Chamber}

Figure 1 shows the setup of three plates in tandem inside the acrylic chamber. The BHI broth in all three plate positions received comparable amounts of nicotine (Figure 2, $p>0.05$ ). The results also show that the amount of nicotine, regardless of source, increases in a dose-dependent manner in all three plates. Lastly, the results also show the projected results of higher levels of nicotine from flavorless ECIG aerosol compared to cigarette smoke (Figure 2) and agree with the expected values shown in Table 1. These data indicate that plate position is not a confounding factor in the results and interpretation of the following experiments.

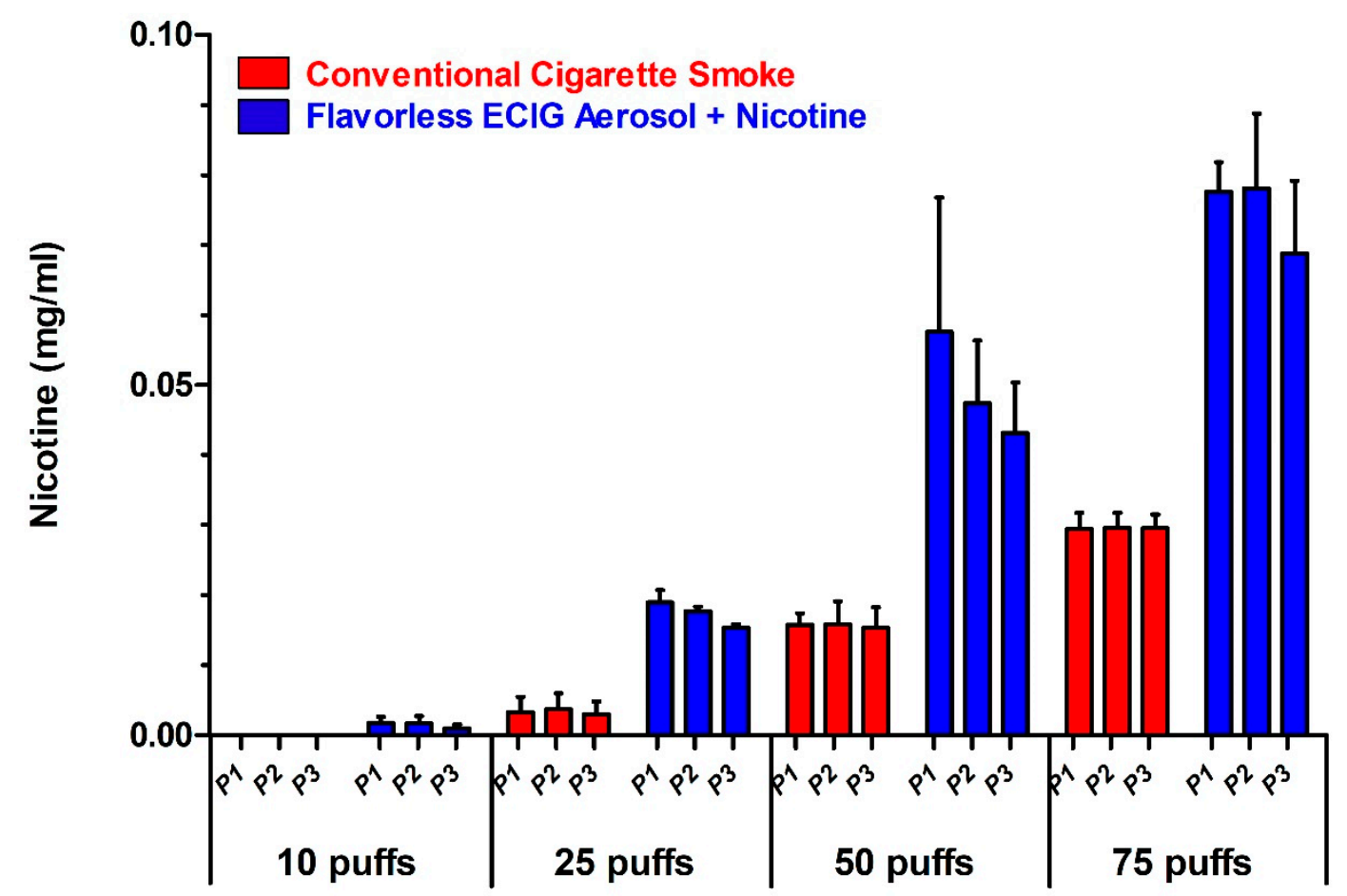

Figure 2. Levels of nicotine in three plates inside the exposure chamber. Nicotine concentrations $(\mathrm{mg} / \mathrm{mL})$ in three plates of brain heart infusion (BHI) broth (i.e., P1, P2 and P3) set up in tandem inside an exposure chamber after 10, 25, 50 and 75 puffs of flavorless ECIG aerosol containing $20 \mathrm{mg} / \mathrm{mL}$ nicotine or conventional cigarette smoke. Each data point is the Mean \pm SE of 3 replicate exposures over 3 separate occasions $(n=3)$.

\subsection{Effects of Electronic Cigarette (ECIG)-Generated Aerosol and Smoke on CFU Counts}

CFU counts of commensal oral streptococci seeded on agar and exposed to puffs of air (control), flavorless ECIG aerosol \pm nicotine and cigarette smoke prior to overnight colony growth are shown in Figure 3. Without exposure (0 puffs), the number of CFUs per agar plate ranged between 37 and 63 for S. gordonii, 25 and 42 for S. intermedius, 35 and 70 for S. mitis, and 65 and 84 for S. oralis. Bacteria exposed to flavorless ECIG aerosol \pm nicotine grew similar numbers of colonies as compared to those exposed to air, although significant differences $(p<0.01)$ between the aerosol with and aerosol without nicotine exist for S. gordonii and S. mitis at 75 and 50 puffs, respectively (Figure 3). In drastic contrast, bacteria exposed to 50 or 75 puffs of cigarette smoke yielded no colonies at all. Our results indicate 
a profound toxic effect of cigarette smoke and a far lower toxic effect of flavorless ECIG aerosol on commensal oral streptococci.
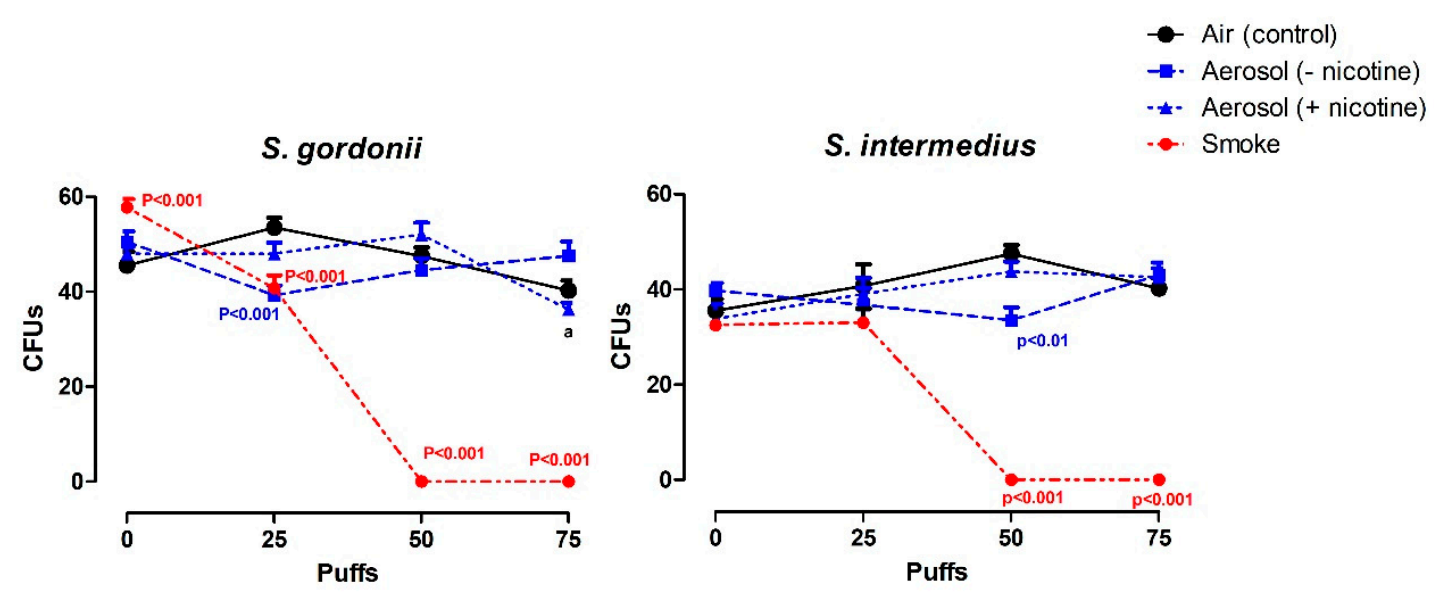

S. mitis

\section{S. oralis}
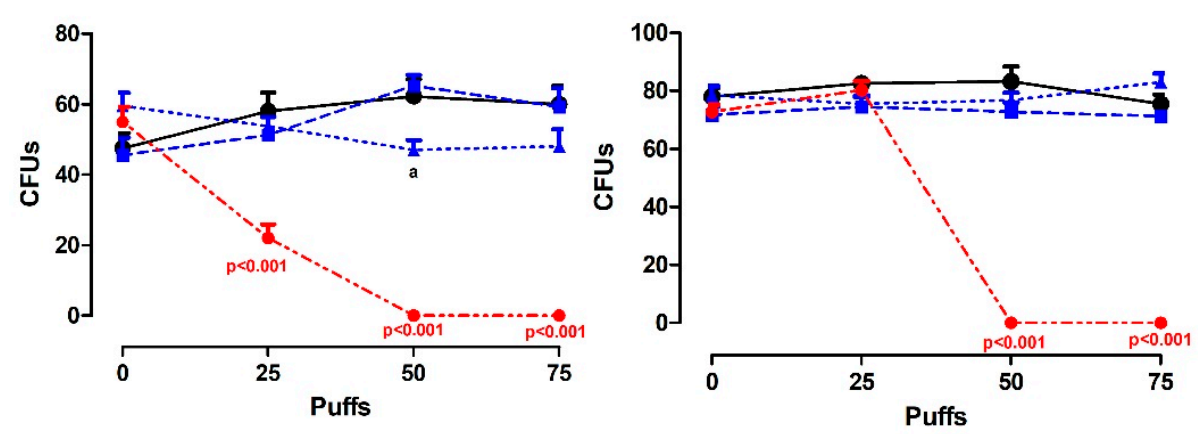

Figure 3. Effect of air, flavorless ECIG aerosol $\left( \pm 20 \mathrm{mg} / \mathrm{mL}\right.$ nicotine), or smoke (Marlboro ${ }^{\circledR}$ Red cigarette) on colony-forming unit (CFU) counts. Each data point is Mean \pm standard error (SE), $n=4$ (average of triplicates from each quadrant of an agar plate), $\mathrm{p}$ values indicate significance from control. $\mathrm{a}=p<0.01$ between aerosol with nicotine and without nicotine.

\subsection{Effects of ECIG-Generated Aerosol and Smoke on Colony Size}

Besides the obvious absence of colonies following exposure to 50 and 75 puffs of smoke, colonies exposed to 25 puffs of cigarette smoke also appear to have a smaller size compared to those colonies exposed to air or flavorless ECIG aerosol \pm nicotine. Figure $4 \mathrm{~A}$ displays the average area of colony sizes for S. gordonii, S. intermedius, S. mitis and S. oralis without exposure (0 puffs) which are $0.543 \pm 0.023$, $0.244 \pm 0.015,0.339 \pm 0.018$ and $0.110 \pm 0.003 \mathrm{~mm}^{2}$, respectively. Figure $4 \mathrm{~B}$ highlights the smaller sizes of colonies for all bacteria after exposure to 25 puffs of smoke compared to colonies after exposure to zero puffs. Since no colonies of S. intermedius, S. mitis and S. oralis were able to grow on agar plates after 50 and 75 puffs of smoke, these are not shown in Figure 4B. However, exposure of $S$. gordonnii to 50 puffs smoke did reduce colony size by $71 \%$ as compared to 0 puffs and $57 \%$ as compared to 25 puffs. Colony sizes after exposure to $0,25,50$ and 75 puffs of air (control), flavorless ECIG aerosol \pm nicotine and cigarette smoke are quantified in Figure $4 \mathrm{C}$. The average colony size of all bacteria exposed to 25 puffs of smoke are significantly smaller $(p<0.01$ to $p<0.001)$ than the controls. Flavorless ECIG aerosol without nicotine also appears to cause a slight increase $(p<0.01)$ on the colony size of $S$. gordonii after exposure to 50 puffs as compared to control (Figure 4C). In all other species tested there are no significant differences among colony sizes after exposure to ECIG aerosol \pm nicotine compared to control (Figure 4C). 
A

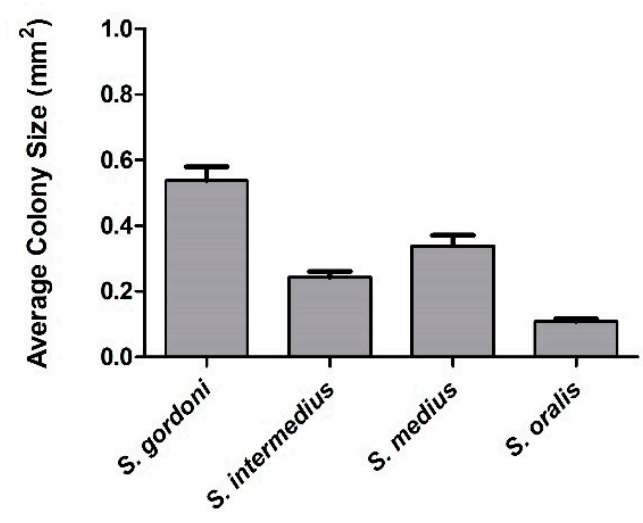

C

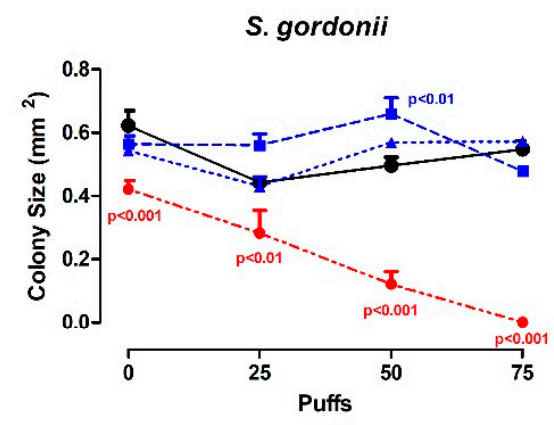

S. mitis

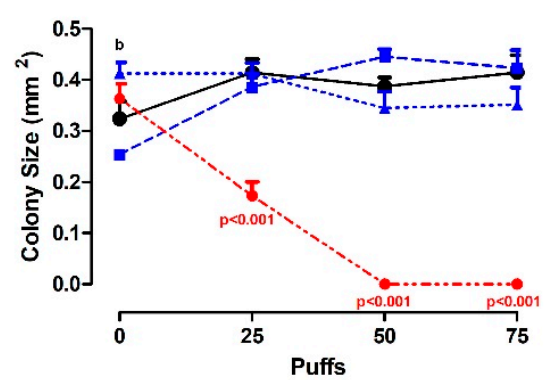

B
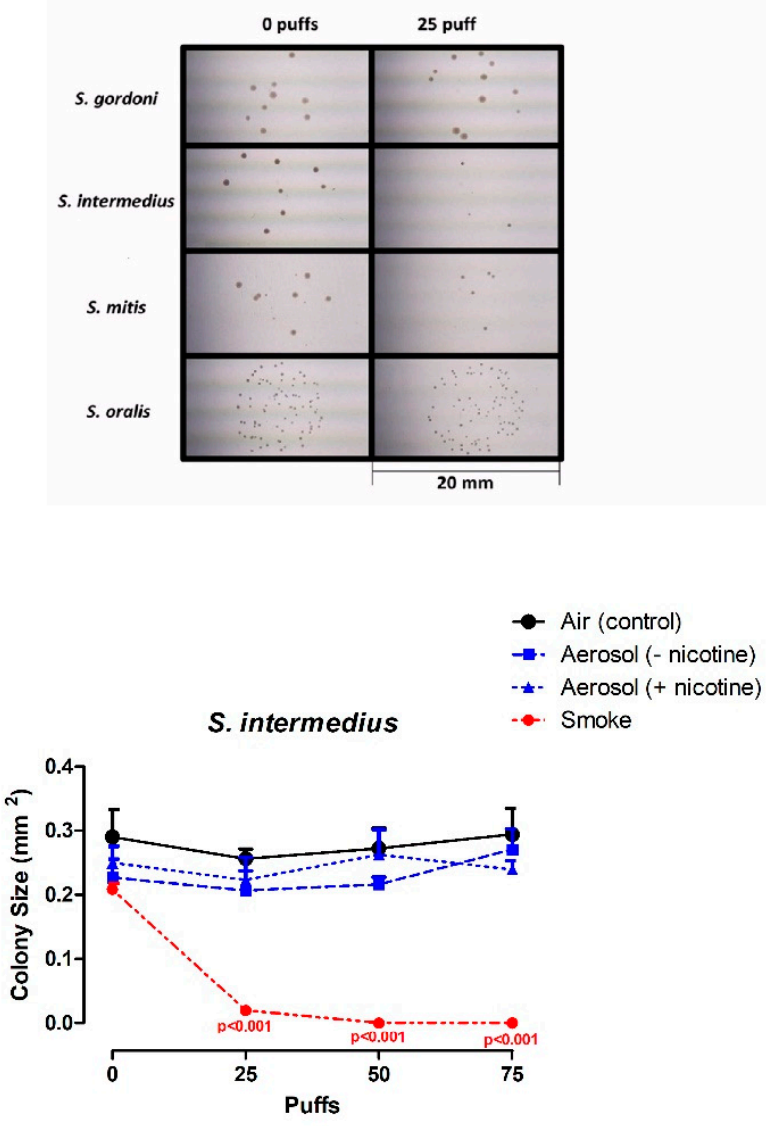

S. oralis

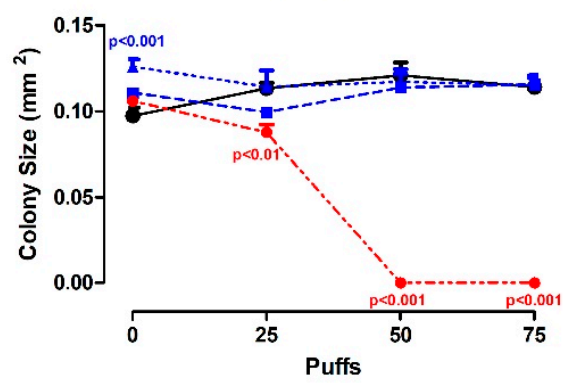

Figure 4. Effect of air, flavorless ECIG aerosol $\left( \pm 20 \mathrm{mg} / \mathrm{mL}\right.$ nicotine), or smoke (Marlboro ${ }^{\circledR}$ Red cigarette) on CFU size. (A) Average colony size of commensal oral streptococci. The average of the three largest colonies in each quadrant of four agar plate $(n=16)$ were used to determine mean colony size for all bacteria at every exposure. Each data point is the Mean $\pm \mathrm{SE}\left(\mathrm{mm}^{2}\right)$. (B) Representative images of colony sizes of commensal oral streptococci following exposure of 0 and 25 puffs of smoke (Marlboro ${ }^{\circledR}$ Red cigarette). Each frame is $20 \mathrm{~mm}$ long. (C) Effect of air (control), aerosol ( $\pm 20 \mathrm{mg} / \mathrm{mL}$ nicotine), or smoke (Marlboro ${ }^{\circledR}$ Red cigarette) on colony size of commensal oral streptococci. Each data point is Mean $\pm \mathrm{SE}, n=4$, p values indicate significance from control. $\mathrm{b}=p<0.001$ between aerosol with nicotine and without nicotine.

\subsection{Effects of ECIG-Generated Aerosol and Smoke on Bacterial Biofilms}

Figure 5 illustrates the formation of single-species bacterial biofilms grown in $50 \% \mathrm{BHI}(\mathrm{v} / \mathrm{v})$ on plastic coverslips $24 \mathrm{~h}$ after exposure to 0 puffs of air (control), 75 puffs of air (control), flavorless ECIG aerosol \pm nicotine and cigarette smoke. Concentrations above or below $50 \% \mathrm{BHI}$ resulted in either 
mostly planktonic bacteria or not enough biofilm growth, respectively (data not shown). As shown, each of these species is able to grow biofilms after exposure to air (control) and flavorless ECIG aerosol \pm nicotine, but not cigarette smoke. Compared to air exposures ( 0 and 75 puffs), 75 puffs of flavorless ECIG aerosol \pm nicotine is permissive for biofilm formation and growth regardless of the overall architecture of bacterial communities for all four species. Although debatable, exposure to ECIG aerosol \pm nicotine may have yielded a lower overall amount of biofilm growth in all species when compared to air exposure. Since Figure 5 is merely qualitative data, it is hard to draw strong conclusions about this point. Notwithstanding this, it is also obvious that such treatments still allow for biofilm growth. These results indicate that flavorless ECIG aerosol \pm nicotine has at most a modest effect on oral commensal streptococci biofilm formation and growth under these conditions.

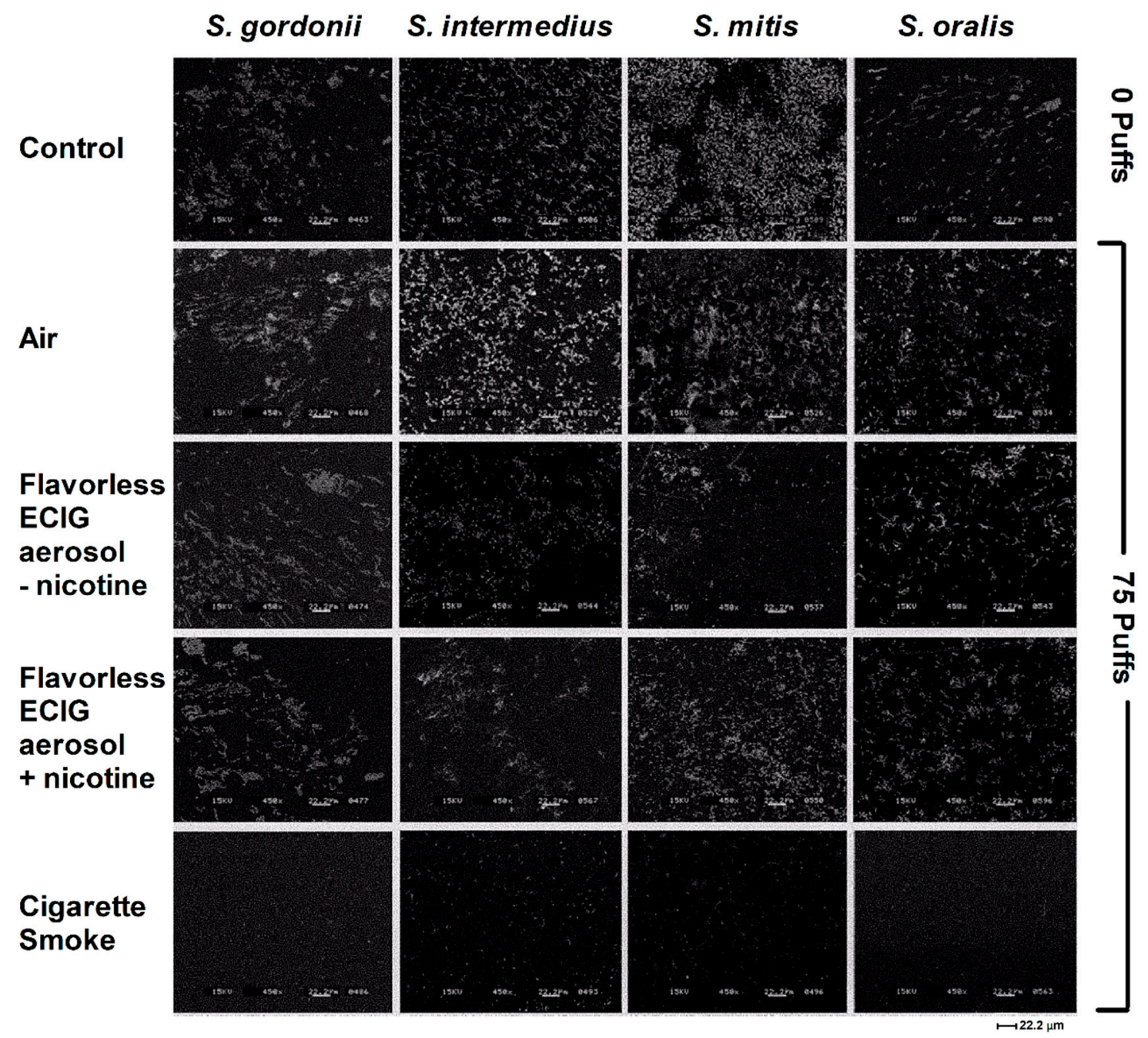

Figure 5. Effect of air, flavorless ECIG aerosol ( $\pm 20 \mathrm{mg} / \mathrm{mL}$ nicotine), or smoke (Marlboro ${ }^{\circledR}$ Red cigarette) on biofilm formation. Representative images of biofilm formation for commensal oral streptococci following exposure to 0 puffs of air (control) or 75 puffs of air (control), aerosol ( $\pm 20 \mathrm{mg} / \mathrm{mL}$ nicotine) and smoke (Marlboro ${ }^{\circledR}$ Red cigarette). All images were acquired at $450 \times$ using an acceleration voltage of $15 \mathrm{kV}$.

\section{Discussion}

The current work demonstrates that flavorless ECIG aerosol \pm nicotine has little to no toxic effect on the in vitro growth of the four oral commensal streptococci tested here. Our data show that CFUs for all four species exposed to flavorless ECIG aerosol \pm nicotine can grow to similar numbers and to similar sizes as compared to their untreated counterparts. Our data also demonstrate that bacteria 
attached to coverslips and exposed to flavorless ECIG aerosol \pm nicotine are also able to grow biofilms like their untreated controls. However, when bacteria are exposed to cigarette smoke, the growth of colonies and biofilms is severely impaired or completely obliterated. Furthermore, it is evident that nicotine is not the culprit of this impairment since ECIG aerosol contained a higher concentration of nicotine than cigarette smoke on a per puff basis (Figure 2). Based on these results, we propose that flavorless ECIG aerosol \pm nicotine does no apparent harm to these four oral bacteria under the conditions tested. However, it remains to be seen what effect the addition of various flavors to the E-liquid would have on the growth of these streptococcal bacteria; work which is currently underway in our laboratory.

While the CFU data and the colony size data indicate that aerosol ( \pm nicotine) has little or no effect on bacterial survival and growth, it could also be argued that biofilm formation is somewhat dampened when bacteria (particularly S. mitis) are exposed to aerosol without nicotine. Furthermore, this effect appears to be reversed when nicotine is added to the aerosol. If true, this would mean that the base humectants (i.e., vaporized propylene glycol and glycerol) may have an inhibitory effect on bacterial survival and growth while nicotine (at the dose tested) has a stimulatory effect on bacterial survival and growth. However, without further experimental evidence, we cannot state definitely that this is actually the case. Consequently, our laboratory is currently investigating the effects of bubbling aerosol ( \pm nicotine) into BHI broth before allowing for planktonic growth of these streptococcal bacteria.

Overall, flavorless ECIG aerosol ( \pm nicotine) appears to have little or no effect on CFU number and colony size of all bacteria tested (Figures 3 and 4). S. gordonii and S. intermedius exhibit a slight decrease in CFU numbers when exposed to 25 and 50 puffs of aerosol without nicotine, respectively, and S. gordonii exhibits a slight increase in colony size when exposed to 50 puffs of aerosol without nicotine. Furthermore, the presence or absence of nicotine in the flavorless ECIG aerosol also appears to have little effect on CFU number and colony size of all streptococci tested. One may argue that such differences are solely based on the treatments and, in fact, ECIG aerosol ( \pm nicotine) does have a slight but significant effect on the growth of these oral bacteria. However, due to the small changes seen, one may also argue that these differences are due to inherent variability associated with CFU plating [41]. On a related subject, it is also worth noting that this study does not address the number of bacteria within each colony. Therefore, it is possible to find different bacterial densities before and after treatments. A modest indication of low variability in bacterial density is seen in Figure 5 where we can observe the overall effect of treatments on the density of micro-colonies. The results of this investigation are comparable to the results of Huang et al. (2014) who report no significant difference in planktonic growth of $S$. gordonii in trypticase soy broth growth media or of CFU counts on tryptic soy agar plates at nicotine concentrations below $1 \mathrm{mg} / \mathrm{mL}$ [31], although nicotine concentrations between 1 and $4 \mathrm{mg} / \mathrm{mL}$ appeared to stimulate $S$. gordonii planktonic growth in a dose-dependent manner. It is most likely that the effect of nicotine on streptococcal bacteria is species-dependent, since Li et al. (2014) determined that nicotine had little effect on S. sanguinis biofilm formation, but increased S. mutans biofilm formation [30].

Oral bacteria live in polymicrobial communities [42], even when exposed to cigarette smoke. The study by Shah et al. (2017) indicates that, in polymicrobial biofilms, commensal species typically suffer and struggle to grow in the presence of tobacco smoke while pathogenic species thrive under the same conditions [43]. The decrease in growth of commensal bacteria exposed to cigarette smoke (Figures 3-5) may be due to down regulation of important metabolic factors in the commensal species [43]. Interestingly, Zonuz et al. (2008) reported accelerated growth of S. sanguinis and S. mutans in the vicinity of cigarette smoke [44] —an apparently contradictory finding. The findings of the present study are in agreement with Shah et al. (2017), in which commensal bacteria are unable to form single-species biofilms when exposed to cigarette smoke. Assuming the microbial landscape within the oral cavity shifts toward poor oral health in response to cigarette smoke, as Shah et al. (2017) indicate, this could ultimately lead to more severe pathophysiologic problems [43]. For example, the report by Bagaitkar et al. (2011) suggests that cigarette smoke extract augments the persistence of $P$. gingivalis 
in biofilms with S. gordonii by elevated expression of major fimbrial antigen [33]. P. gingivalis is a Gram-negative pathogenic bacterium and a principal periodontitis-inducing agent [45,46]. Periodontal pathogens induce systemic inflammation, ultimately leading to increased risk of cardiovascular disease such as atherosclerosis $[47,48]$. While flavorless ECIG aerosol has no effect on our commensal bacteria's ability to form biofilms (Figure 5), it is important to test the effects of conventional cigarette smoke and ECIG aerosol with mixed-species biofilms to determine the effects of the same environmental agents in an open system. The results of such experiments will give a much better understanding of the effects of smoke and ECIG aerosol on oral microbial communities. Our experimental design also tested only one strain of bacteria at a time. Interactions between strains of commensal bacteria, as well as with pathogenic bacteria, should be investigated to determine ultimately if the effect of flavorless ECIG-aerosol is also different than that of smoke in mixed species biofilms. To best address this question, the bacteria should be cultured in an open system following exposure. An open system design would resemble the natural oral environment in the context of mixtures of oral microbiota combined with salivary flow, which aids in clearance of external materials from the oral cavity.

As CFU counts, colony size and biofilm formation obtained from this investigation indicate, we are confident that flavorless ECIG aerosol has a less drastic effect on the oral commensal bacteria tested than cigarette smoke. However, this study does have limitations. The in-house prepared E-liquid used in this study represents a single rendition of E-liquid and does not represent the flavored preferences of most ECIG users, particularly high-school teens who are enticed by the many exotic flavors offered by ECIG companies. In addition, the only concentration of nicotine used is $20 \mathrm{mg} / \mathrm{mL}$ and the only ratio of propylene glycol to vegetable glycerin is 1:1 $\mathrm{v} / \mathrm{v}$. Furthermore, the only bacteria tested were these four commensal streptococci, which were evaluated individually. Red complex bacteria, such as P. gingivalis, Aggregatibacter actinomycetemcomitans, Tannerella forsythia or Treponema denticola were not included in this study, presenting another important limitation. Therefore, conclusions concerning the effects of ECIG aerosol on the survival and growth of commensal bacteria must be considered within the context of variability in the composition of commercially available E-liquids and the bacteria evaluated. Another limitation is the fact that flavorless ECIG-aerosol and conventional cigarette smoke are not identical by nature [49]. For example, the E-liquid vaporization process versus the tobacco combustion process result in exposure chambers with different physical environments such as temperature and humidity [40]. Furthermore, the volume of the human oral cavity, as determined by height, width and depth [50], is approximately $230 \mathrm{~cm}^{3}$, much smaller than the $2100 \mathrm{~cm}^{3}$ calculated for the exposure chambers used in this study [40]. This means that the effect of flavorless ECIG-aerosol or conventional cigarette smoke on oral commensal streptococci could be minimized in this investigation as compared to their effects in vivo. Alternatively, the in vitro results of this study could also be amplified when comparing the effect of aerosol and smoke on oral commensal streptococci. For example, our results clearly show that the effects of 50 puffs of conventional smoke strongly obliterates colony or biofilm formation in every oral species tested. However, it is important to note that our in vitro experiments do not have a mechanism for removal of aerosol or smoke materials as saliva would in the oral cavity in vivo, but rather are constantly exposed to these materials for the duration of the experiments. In addition to lacking removal mechanisms of aerosol or smoke material, the slow buildup of aerosol and especially smoke within the chamber very likely changes the environment within the chamber to be less oxygenated, a condition which undoubtedly affects the growth of even facultative bacteria. Consequently, the results obtained from using this exposure system may (in part) be due to decreased oxygenation.

Moreover, since our experimental design does not exhibit the properties of an open system, it cannot determine whether the overall effect of cigarette smoke on oral commensal bacteria is bacteriostatic or bactericidal. In the scenario where the smoke is bacteriostatic, such experimental design will allow for the removal of potential bacteriostatic compounds and once the cigarette smoke materials fall below the minimal inhibitory concentration, the bacterial communities will be able to resume growth. It is important to note that the growth and/or architecture of biofilm communities may 
be altered at this point as a result of such cigarette smoke effects. Alternatively, if the smoke materials are bactericidal, the bacteria will be dead even after the removal of such materials. This aspect deserves further study because the livelihood of the commensal bacteria is important to the homeostasis of the oral cavity, keeping it and the entire physiological system healthy. Consequently, we are currently in the process of developing an open system design to address these questions.

\section{Conclusions}

This study indicates that flavorless ECIG aerosol ( \pm nicotine) is less detrimental to the survival and growth of oral commensal streptococci than conventional cigarette smoke. This study opens the door for subsequent studies that could address the effect of flavorless ECIG aerosol on oral epithelial cells as well as the addition of flavoring agents to test all the aforementioned biological models.

Author Contributions: G.A.C. and D.L.P. conceived the study and designed the experiments. G.A.C., M.T.S., J.M.N., E.K.L. and D.L.P. performed the experiments. D.L.P. performed the HPLC analysis. M.T.S. determined CFU counts and colony size. J.M.N. prepared biofilms for SEM imaging. E.K.L. optimized biofilm experiments and imaged biofilms using SEM. G.A.C. oversaw the experiments and D.L.P. provided insight to the project. G.A.C. and D.L.P. contributed to the writing of the manuscript.

Acknowledgments: This work is supported by an intramural grant from the DeBusk College of Osteopathic Medicine. The authors gratefully acknowledge the technical expertise and assistance provided by Dr. Stan Kunigelis of the Center of Imaging and Analysis at Lincoln Memorial University (LMU) and Dr. Elizabeth McCain at Muhlenberg College (MC). The authors would also like to thank LMU and MC faculty (Drs. Gina DeFranco, Marten Edwards, Stacie Fairley, Douglas Fitzovitch, John Gibbons, Adam Gromley, Julie Hall, Amy Hark, Adam Rollins, Jordanna Sprayberry, Michael Wieting, Bruce Wightman and Jan Zieran) for graciously providing constructive criticism, comments and editorial assistance in the preparation of this manuscript.

Conflicts of Interest: The authors declare that this manuscript was written without any commercial or financial relationships that could be mistaken as a potential conflict of interest.

\section{References}

1. Glantz, S.A.; Bareham, D.W. E-Cigarettes: Use, Effects on Smoking, Risks, and Policy Implications. Ann. Rev. Public Health 2018, 39, 215-235. [CrossRef]

2. Hajek, P.; Etter, J.-F.; Benowitz, N.; Eissenberg, T.; McRobbie, H. Electronic cigarettes: Review of use, content, safety, effects on smokers and potential for harm and benefit. Addiction 2014, 109, 1801-1810. [CrossRef]

3. Jensen, R.P.; Luo, W.; Pankow, J.F.; Strongin, R.M.; Peyton, D.H. Hidden formaldehyde in e-cigarette aerosols. N. Engl. J. Med. 2015, 372, 392-394. [CrossRef]

4. Holliday, R.; Kist, R.; Bauld, L. E-cigarette vapour is not inert and exposure can lead to cell damage. Evid. Based Dent. 2016, 17, 2-3. [CrossRef]

5. Yu, V.; Rahimy, M.; Korrapati, A.; Xuan, Y.; Zou, A.E.; Krishnan, A.R.; Tsui, T.; Aguilera, J.A.; Advani, S.; Alexander, L.E.C.; et al. Electronic cigarettes induce DNA strand breaks and cell death independently of nicotine in cell lines. Oral Oncol. 2016, 52, 58-65. [CrossRef]

6. Muthumalage, T.; Prinz, M.; Ansah, K.O.; Gerloff, J.; Sundar, I.K.; Rahman, I. Inflammatory and Oxidative Responses Induced by Exposure to Commonly Used e-Cigarette Flavoring Chemicals and Flavored e-Liquids without Nicotine. Front. Physiol. 2017, 8, 1130. [CrossRef]

7. Bahl, V.; Lin, S.; Xu, N.; Davis, B.; Wang, Y.; Talbot, P. Comparison of electronic cigarette refill fluid cytotoxicity using embryonic and adult models. Reprod. Toxicol. 2012, 34, 529-537. [CrossRef]

8. Leigh, N.J.; Tran, P.L.; O'Connor, R.J.; Goniewicz, M.L. Cytotoxic effects of heated tobacco products (HTP) on human bronchial epithelial cells. Tob. Control 2018, 27, s26-s29. [CrossRef]

9. Leigh, N.J.; Lawton, R.I.; Hershberger, P.A.; Goniewicz, M.L. Flavourings significantly affect inhalation toxicity of aerosol generated from electronic nicotine delivery systems (ENDS). Tob. Control 2016, 25, ii81-ii87. [CrossRef]

10. Sundar, I.K.; Javed, F.; Romanos, G.E.; Rahman, I. E-cigarettes and flavorings induce inflammatory and pro-senescence responses in oral epithelial cells and periodontal fibroblasts. Oncotarget 2016, 7, 77196-77204. [CrossRef]

11. Burne, R.A. Oral Streptococci... Products of Their Environment. J. Dent. Res. 1998, 77, 445-452. [CrossRef] [PubMed] 
12. Rosan, B.; Lamont, R.J. Dental plaque formation. Microbes Infect. 2000, 2, 1599-1607. [CrossRef]

13. Kolenbrander, P.E. Oral Microbial Communities: Biofilms, Interactions, and Genetic Systems. Annu. Rev. Microbiol. 2000, 54, 413-437. [CrossRef]

14. Hajishengallis, G.; Lamont, R.J. Beyond the red complex and into more complexity: The polymicrobial synergy and dysbiosis (PSD) model of periodontal disease etiology. Mol. Oral Microbiol. 2012, 27, 409-419. [CrossRef]

15. Aas, J.A.; Paster, B.J.; Stokes, L.N.; Olsen, I.; Dewhirst, F.E. Defining the Normal Bacterial Flora of the Oral Cavity. J. Clin. Microbiol. 2005, 43, 5721-5732. [CrossRef] [PubMed]

16. Colombo, A.V.; da Silva, C.M.; Haffajee, A.; Colombo, A.P.V. Identification of intracellular oral species within human crevicular epithelial cells from subjects with chronic periodontitis by fluorescence in situ hybridization. J. Periodontal Res. 2007, 42, 236-243. [CrossRef]

17. Garnier, F.; Gerbaud, G.; Courvalin, P.; Galimand, M. Identification of clinically relevant viridans group streptococci to the species level by PCR. J. Clin. Microbiol. 1997, 35, 2337-2341. [PubMed]

18. Kolenbrander, P.E.; Andersen, R.N.; Blehert, D.S.; Egland, P.G.; Foster, J.S.; Palmer, R.J. Communication among oral bacteria. Microbiol. Mol. Biol. Rev. 2002, 66, 486-505. [CrossRef]

19. Kolenbrander, P.E.; Egland, P.G.; Diaz, P.I.; Palmer, R.J. Genome-genome interactions: Bacterial communities in initial dental plaque. Trends Microbiol. 2005, 13, 11-15. [CrossRef] [PubMed]

20. Teles, F.R.; Teles, R.P.; Uzel, N.G.; Song, X.Q.; Torresyap, G.; Socransky, S.S.; Haffajee, A.D. Early microbial succession in re-developing dental biofilms in periodontal health and disease. J. Periodontal Res. 2012, 47, 95-104. [CrossRef] [PubMed]

21. Socransky, S.S.; Haffajee, A.D.; Cugini, M.A.; Smith, C.; Kent, R.L. Microbial complexes in subgingival plaque. J. Clin. Periodontol. 1998, 25, 134-144. [CrossRef]

22. Heller, D.; Helmerhorst, E.J.; Gower, A.C.; Siqueira, W.L.; Paster, B.J.; Oppenheim, F.G. Microbial Diversity in the Early in Vivo-Formed Dental Biofilm. Appl. Environ. Microbiol. 2016, 82, 1881-1888. [CrossRef]

23. Hasegawa, Y.; Mans, J.J.; Mao, S.; Lopez, M.C.; Baker, H.V.; Handfield, M.; Lamont, R.J. Gingival epithelial cell transcriptional responses to commensal and opportunistic oral microbial species. Infect. Immun. 2007, 75, 2540-2547. [CrossRef] [PubMed]

24. Thurnheer, T.; Belibasakis, G.N. Streptococcus oralis maintains homeostasis in oral biofilms by antagonizing the cariogenic pathogen Streptococcus mutans. Mol. Oral Microbiol. 2018, 33, 234-239. [CrossRef]

25. Gross, E.L.; Beall, C.J.; Kutsch, S.R.; Firestone, N.D.; Leys, E.J.; Griffen, A.L. Beyond Streptococcus mutans: Dental caries onset linked to multiple species by $16 \mathrm{~S}$ rRNA community analysis. PLoS ONE 2012, 7, e47722. [CrossRef]

26. Huang, X.; Browngardt, C.M.; Jiang, M.; Ahn, S.-J.; Burne, R.A.; Nascimento, M.M. Diversity in Antagonistic Interactions between Commensal Oral Streptococci and Streptococcus mutans. Caries Res. 2018, 52, 88-101. [CrossRef]

27. Liu, Y.; Palmer, S.R.; Chang, H.; Combs, A.N.; Burne, R.A.; Koo, H. Differential oxidative stress tolerance of Streptococcus mutans isolates affects competition in an ecological mixed-species biofilm model. Environ. Microbiol. Rep. 2018, 10, 12-22. [CrossRef]

28. Herrero, E.R.; Slomka, V.; Bernaerts, K.; Boon, N.; Hernandez-Sanabria, E.; Passoni, B.B.; Quirynen, M.; Teughels, W. Antimicrobial effects of commensal oral species are regulated by environmental factors. J. Dent. 2016, 47, 23-33. [CrossRef] [PubMed]

29. Holmlund, A.; Lampa, E.; Lind, L. Oral health and cardiovascular disease risk in a cohort of periodontitis patients. Atherosclerosis 2017, 262, 101-106. [CrossRef] [PubMed]

30. Li, M.; Huang, R.; Zhou, X.; Zhang, K.; Zheng, X.; Gregory, R.L. Effect of nicotine on dual-species biofilms of Streptococcus mutans and Streptococcus sanguinis. FEMS Microbiol. Lett. 2014, 350, 125-132. [CrossRef]

31. Huang, R.; Li, M.; Ye, M.; Yang, K.; Xu, X.; Gregory, R.L. Effects of Nicotine on Streptococcus gordonii Growth, Biofilm Formation, and Cell Aggregation. Appl. Environ. Microbiol. 2014, 80, 7212-7218. [CrossRef]

32. Tomar, S.L.; Asma, S. Smoking-Attributable Periodontitis in the United States: Findings from NHANES III. J. Periodontol. 2000, 71, 743-751. [CrossRef] [PubMed]

33. Bagaitkar, J.; Daep, C.A.; Patel, C.K.; Renaud, D.E.; Demuth, D.R.; Scott, D.A. Tobacco smoke augments Porphyromonas gingivalis-Streptococcus gordonii biofilm formation. PLoS ONE 2011, 6, e27386. [CrossRef] [PubMed] 
34. Moon, J.-H.; Lee, J.-H.; Lee, J.-Y. Subgingival microbiome in smokers and non-smokers in Korean chronic periodontitis patients. Mol. Oral Microbiol. 2015, 30, 227-241. [CrossRef]

35. Calafat, A.M. Determination of tar, nicotine, and carbon monoxide yields in the mainstream smoke of selected international cigarettes. Tob. Control 2004, 13, 45-51. [CrossRef]

36. Cobb, E.; Hall, J.; Palazzolo, D.L. Induction of Metallothionein Expression After Exposure to Conventional Cigarette Smoke but Not Electronic Cigarette (ECIG)-Generated Aerosol in Caenorhabditis elegans. Front. Physiol. 2018, 9, 426. [CrossRef]

37. Palazzolo, D.L.; Nelson, J.M.; Ely, E.A.; Crow, A.P.; Distin, J.; Kunigelis, S.C. The Effects of Electronic Cigarette (ECIG)-Generated Aerosol and Conventional Cigarette Smoke on the Mucociliary Transport Velocity (MTV) Using the Bullfrog (R. catesbiana) Palate Paradigm. Front. Physiol. 2017, 8, 1023. [CrossRef]

38. Trehy, M.L.; Ye, W.; Hadwiger, M.E.; Moore, T.W.; Allgire, J.F.; Woodruff, J.T.; Ahadi, S.; Black, J.C.; Westenberger, B.J. Analysis of Electronic Cigarette Cartridges, Refill Solutions, and Smoke for Nicotine and Nicotine Related Impurities. J. Liq. Chromatogr. Relat. Technol. 2011, 34, 1442-1458. [CrossRef]

39. Murray, J. Nicotine and What Else? HPLC Elution Optimization for the Analysis of Alkaloids Found in Electronic Cigarettes. Honors Theses, 2014. Available online: https://scholar.utc.edu/honors-theses/3 (accessed on 21 March 2019).

40. Palazzolo, D.L.; Crow, A.P.; Nelson, J.M.; Johnson, R.A. Trace Metals Derived from Electronic Cigarette (ECIG) Generated Aerosol: Potential Problem of ECIG Devices That Contain Nickel. Front Physiol. 2017, 7. [CrossRef]

41. Sutton, S. Accuracy of plate counts. J. Valid. Technol. 2011, 17, 42-46.

42. Kolenbrander, P.E. Multispecies communities: Interspecies interactions influence growth on saliva as sole nutritional source. Int. J. Oral Sci. 2011, 3, 49-54. [CrossRef]

43. Shah, S.A.; Ganesan, S.M.; Varadharaj, S.; Dabdoub, S.M.; Walters, J.D.; Kumar, P.S. The making of a miscreant: Tobacco smoke and the creation of pathogen-rich biofilms. NPJ Biofilms Microbiomes 2017, 3, 26. [CrossRef]

44. Zonuz, A.T.; Rahmati, A.; Mortazavi, H.; Khashabi, E.; Farahani, R.M.Z. Effect of cigarette smoke exposure on the growth of Streptococcus mutans and Streptococcus sanguis: An in vitro study. Nicotine Tob. Res. 2008, 10, 63-67. [CrossRef]

45. Abiko, Y.; Sato, T.; Mayanagi, G.; Takahashi, N. Profiling of subgingival plaque biofilm microflora from periodontally healthy subjects and from subjects with periodontitis using quantitative real-time PCR. J. Periodont. Res. 2010, 45, 389-395. [CrossRef]

46. Genco, C.A.; Van Dyke, T.; Amar, S. Animal models for Porphyromonas gingivalis-mediated periodontal disease. Trends Microbiol. 1998, 6, 444-449. [CrossRef]

47. Olsen, I.; Progulske-Fox, A. Invasion of Porphyromonas gingivalis strains into vascular cells and tissue. J. Oral Microbiol. 2015, 7. [CrossRef] [PubMed]

48. Pussinen, P.J.; Tuomisto, K.; Jousilahti, P.; Havulinna, A.S.; Sundvall, J.; Salomaa, V. Endotoxemia, immune response to periodontal pathogens, and systemic inflammation associate with incident cardiovascular disease events. Arterioscler. Thromb. Vasc. Biol. 2007, 27, 1433-1439. [CrossRef] [PubMed]

49. Sosnowski, T.R.; Odziomek, M. Particle Size Dynamics: Toward a Better Understanding of Electronic Cigarette Aerosol Interactions with the Respiratory System. Front. Physiol. 2018, 9, 853. [CrossRef]

50. Kaufman, J.W.; Farahmand, K. In vivo measurements of human oral cavity heat and water vapor transport. Respir. Physiol. Neurobiol. 2006, 150, 261-277. [CrossRef]

(C) 2019 by the authors. Licensee MDPI, Basel, Switzerland. This article is an open access article distributed under the terms and conditions of the Creative Commons Attribution (CC BY) license (http://creativecommons.org/licenses/by/4.0/). 